\title{
List of Countries and Country Codes
}

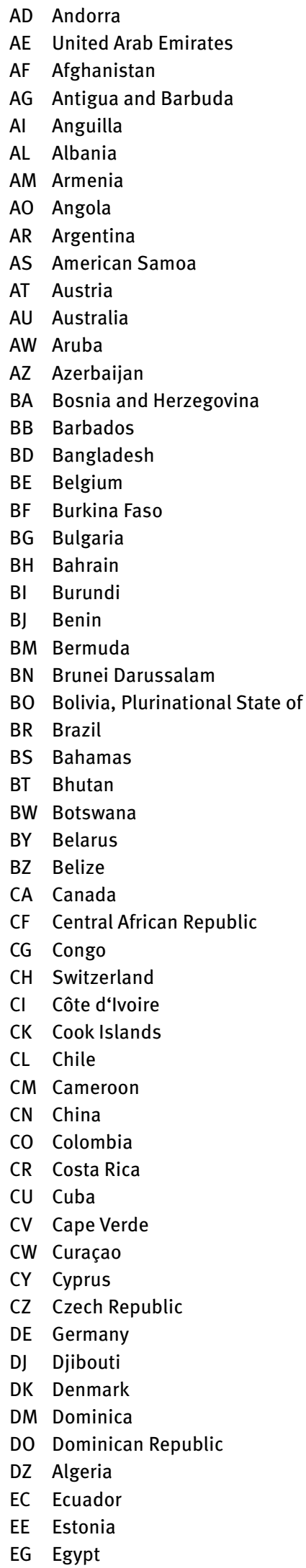

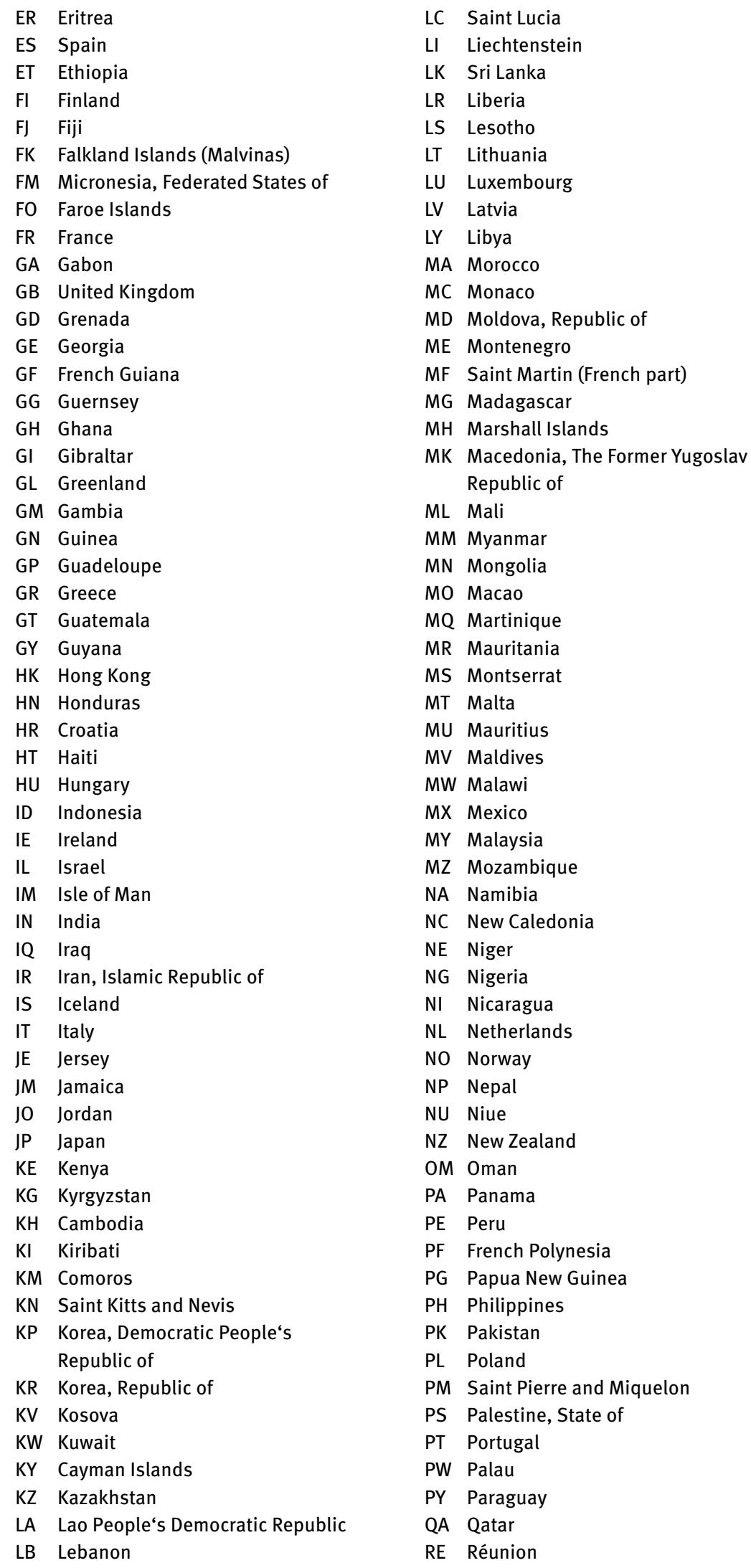




$\begin{array}{ll}\text { RO } & \text { Romania } \\ \text { RS } & \text { Serbia } \\ \text { RU } & \text { Russian Federation } \\ \text { RW } & \text { Rwanda } \\ \text { SA } & \text { Saudi Arabia } \\ \text { SB } & \text { Solomon Islands } \\ \text { SC } & \text { Seychelles } \\ \text { SD } & \text { Sudan } \\ \text { SE } & \text { Sweden } \\ \text { SG } & \text { Singapore } \\ \text { SH } & \text { Saint Helena, Ascension and Tristan da } \\ & \text { Cunha } \\ \text { SI } & \text { Slovenia } \\ \text { SK } & \text { Slovakia } \\ \text { SL } & \text { Sierra Leone } \\ \text { SM } & \text { San Marino } \\ \text { SN } & \text { Senegal }\end{array}$

$\begin{array}{ll}\text { SR } & \text { Suriname } \\ \text { ST } & \text { Sao Tome and Principe } \\ \text { SV } & \text { El Salvador } \\ \text { SY } & \text { Syrian Arab Republic } \\ \text { SZ } & \text { Swaziland } \\ \text { TC } & \text { Turks and Caicos Islands } \\ \text { TD } & \text { Chad } \\ \text { TG } & \text { Togo } \\ \text { TH } & \text { Thailand } \\ \text { TJ } & \text { Tajikistan } \\ \text { TL } & \text { Timor-Leste } \\ \text { TN } & \text { Tunisia } \\ \text { TO } & \text { Tonga } \\ \text { TR } & \text { Turkey } \\ \text { TT } & \text { Trinidad and Tobago } \\ \text { TW } & \text { Taiwan } \\ \text { TZ } & \text { Tanzania, United Republic of }\end{array}$

\author{
UA Ukraine \\ UG Uganda \\ US United States \\ UY Uruguay \\ UZ Uzbekistan \\ VA Holy See (Vatican City State) \\ VC Saint Vincent and The Grenadines \\ VE Venezuela, Bolivarian Republic of \\ VG Virgin Islands, British \\ VN Viet Nam \\ VU Vanuatu \\ WF Wallis and Futuna \\ WS Samoa \\ YT Mayotte \\ ZA South Africa \\ ZM Zambia \\ ZW Zimbabwe
}

